\title{
The burden of stroke in Brazil in 2016: an analysis of the Global Burden of Disease study findings
}

\author{
Nathalia Matos de Santana ${ }^{1 \dagger}$, Francisco Winter dos Santos Figueiredo ${ }^{2 \dagger}$, Diego Monteiro de Melo Lucena ${ }^{2^{*}}$, \\ Fernando Mayo Soares ${ }^{2}$, Fernando Adami ${ }^{2}$, Luciana de Carvalho Pádua Cardoso ${ }^{1}$ and João Antonio Correa ${ }^{3}$
}

\begin{abstract}
Objective: To analyze the epidemiological stroke data of Brazil according to the Global Burden of Disease (GBD) study in 2016 and secondary data from the GBD database.

Results: The highest percentage of deaths due to stroke in general occurred in individuals aged 70 years or over (60.2\%; 95\% confidence interval [CI] 59.9-60.5\%) followed by that in men (52.9\%; 95\% Cl 52.6-53.2\%). Ischemic stroke was the most common type, accounting for $61.8 \%$ (95\% Cl 61.5-62.1\%) of deaths due to stroke in 2016. Most of the epidemiological indicators (incidence, prevalence, mortality-to-incidence ratio, mortality, disability-adjusted life years, years lost due to disability, and years of life lost) of stroke in general or either type of stroke were higher in men and those aged 70 years or over. Stroke data in Brazil are a major concern and represent a real health challenge for the coming decades. Men and individuals aged 70 years or older appear to represent the groups with the highest epidemiological parameters and risk for the various stroke outcomes. However, this does not mean the female data are irrelevant, which, although representing a lower risk than the male data, also raise the need for policies aimed at prevention and improvement in the treatment of stroke and its sequelae.
\end{abstract}

Keywords: Stroke, Epidemiology, Brazil

\section{Introduction}

Developed countries have experienced a drop in the indicators of mortality due to stroke in recent decades, in contrast to low- and middle-income countries that have shown an increasing trend of morbidity and mortality from this disease [1-3]. Brazil, however, has experienced a downward trend in stroke mortality, albeit at a slower rate than that of developed countries [4-6].

Emerging countries such as Brazil [7] have shown developments and improvements in access to education and technology as well as improvements in primary health care, with an emphasis on prevention [2]. The

\footnotetext{
*Correspondence: Iucenadiego@hotmail.com

${ }^{\dagger}$ Nathalia Matos de Santana and Francisco Winter dos Santos Figueiredo are First authors

${ }^{2}$ Laboratório de Epidemiologia e Análise de Dados, Faculdade de Medicina do ABC, Santo André, SP, Brazil

Full list of author information is available at the end of the article
}

application of these practices has resulted in an increase in life expectancy, changes in lifestyle, and consequently changes in the way people live and take care of their health $[8,9]$.

With these changes, the control, prevention, and treatment of risk factors have been prioritized to decrease mortality due to cardiovascular and cerebrovascular diseases such as stroke [10-12]. In 2010, stroke was considered the leading cause of death [13] and the third cause of disability-adjusted life years (DALYs) [14] worldwide.

However, owing to the rapid changes in the behavior of diseases, it is essential to update epidemiological studies for the adequate formulation of public policies, especially regarding epidemiological parameters related to disease burden. In this context, the objective of the present study was to describe the epidemiological aspects of stroke in Brazil in 2016. 


\section{Main text \\ Methods \\ Study design}

This was a descriptive study with data from the Global Burden of Disease (GBD) study conducted in Brazil in 2016.

\section{Data source}

To understand the epidemiological aspects of diseases in different parts of the world, including Brazil, GBD researchers developed statistical tests to estimate the global burden of 291 diseases in all countries divided into 21 groups [15].

The GBD database is maintained by the Institute for Health Metrics and Evaluation at the University of Washington in Seattle, Washington, USA (http://www.healt hdata.org).

The data sources used to construct the GBD database include representative national surveys, cancer registries, vital records systems, and health care use data and encompass 291 diseases in all countries of the globe separated into 21 groups [15].

Information about GBD data can be found in the GBD Data Input Sources Tool in the GHDx (http://ghdx.healt hdata.org/gbd-2016). The tool allows users to explore the input sources to GBD based on various criteria, and to export and explore the results. The GBD database is maintained by the Institute for Health Metrics and Evaluation at the University of Washington in Seattle, Washington, USA (http://www.healthdata.org).

For Brazil, the main source of mortality data used in the GBD study was the database of the Mortality Information System of the Ministry of Health, adjusted for other national and international sources.

Therefore, this database provides a comprehensive annual assessment of consistent estimates of health loss due to mortality and morbidity of diseases, injuries, and risk factors through approaches, statistical modeling, and metrics, such as incidence, prevalence, mortality, years of life lost (YLL) due to premature mortality, mortality-to-incidence ratio (MIR), years lived with disability (YLD), disability-adjusted life years (DALYs), and healthadjusted life expectancy.

The GBD study uses rigorous methods to nullify biases in the sources and models used to generate estimates based on the complexity of disease epidemiology. In addition, advanced statistical methodologies are used to estimate regional results, thus reducing sampling bias. The results are updated annually for the entire time series and these results supersede earlier versions of the GBD study.

\section{Variables studied}

The variables studied related to stroke were Incidence, Prevalence, Mortality, mortality-to-incidence ratio, YLL, YLD, and DALYs overall and according to sex, age range (15-49, 50-69, and $\geq 70$ years), and type of stroke (ischemic or hemorrhagic) occurring in Brazil in 2016. These data are expressed as number per 100,000 inhabitants. The indicators studied are presented in Table 1.

\section{Data analysis}

Data are presented as absolute frequency and relative frequency. To estimate the mortality-to-incidence ratio (MIR), the Mortality and Incidence rates for stroke were standardized for age and expressed per 100,000 people. The statistical program used to analyze the data was Stata ${ }^{\circledR}$ version 11.0 (StataCorp LLC, College Station, TX, USA).

\section{Results}

In Brazil in 2016, there were 107,258 deaths due to stroke, with the highest numbers observed in men $(56,782$ deaths, $52.9 \%$, 95\% confidence interval [CI] $52.6-53.2 \%)$ and in the group of individuals over

Table 1 Epidemiological indicators, calculations, and interpretation of the results of the indicators

\begin{tabular}{|c|c|c|}
\hline Indicator & Calculation & Interpretation \\
\hline Mortality & No. of deaths/population $\times 100,000$ & Proportion of people who die of a disease \\
\hline Incidence & $\begin{array}{l}\text { No. of new cases detected during a given time period } \times 100,000 / \\
\text { No. of persons at risk of developing the disease during the same } \\
\text { period }\end{array}$ & $\begin{array}{l}\text { Number of new cases of a given disease over a defined period in a } \\
\text { population at risk of developing the disease }\end{array}$ \\
\hline Prevalence & $\begin{array}{l}\text { Number of known cases of the disease in a given period } \times 100,000 / \\
\text { population during the same period }\end{array}$ & $\begin{array}{l}\text { Proportion of people in a given population that present a specific } \\
\text { disease at a particular point in time }\end{array}$ \\
\hline MIR & Mortality rate/incidence rate & Indicator used to estimate survival of any disease in 5 years \\
\hline DALYS & $Y L L+Y L D$ & Years of healthy life lost \\
\hline YLD & $\begin{array}{l}\text { Number of incident cases } x \text { weight of disability } x \text { average duration } \\
\text { until remission or death }\end{array}$ & $\begin{array}{l}\text { The number of years that an individual lives with a functional } \\
\text { impairment caused by an illness }\end{array}$ \\
\hline YLL & Number of deaths $x$ standard life expectancy at the age of death & $\begin{array}{l}\text { The number of years a person could have lived if the illness that } \\
\text { killed him had not occurred }\end{array}$ \\
\hline
\end{tabular}


70 years of age $(64,582$ deaths, $60.2 \%$, 95\% CI $59.9-$ $60.5 \%)$. The ischemic type of stroke accounted for the most deaths (66,261 deaths, $61.8 \%$. 95\% CI 61.5-62.1\%). Regarding the burden of stroke per 100,000 Brazilian inhabitants in 2016, there was an incidence of 138.91, mortality of 63.15, 1437.74 DALYs, 14.77 YLD, and 1337.74 YLL (Table 2).

Regarding the burden of stroke according to sex and type of stroke, higher epidemiological indicators were observed among men compared with women, except for the prevalence of hemorrhagic stroke and the number of YLD, which were higher in women (Table 3).

Regarding the burden of stroke according to age group and type of stroke, the majority of epidemiologi$\mathrm{cal}$ indicators were higher in the age group of 70 years or older. However, the MIR was higher among individuals aged $15-49$ years $(M I R=0.25)$ than that observed in those aged $50-69$ years $(\mathrm{MIR}=0.04)$ or 70 years or older $(\mathrm{MIR}=0.09)$ for the general stroke category as well as the hemorrhagic subtype (15-49 years, $\mathrm{MIR}=0.50 ; \quad 50-69$ years, $\mathrm{MIR}=0.10 ; \geq 70$ years, MIR $=0.16)($ Table 3).

\section{Discussion}

When describing the burden of Stroke in Brazil in 2016, it was observed that:

\begin{tabular}{|c|c|c|}
\hline Characteristic & $\mathbf{n}$ & $\%(95 \% \mathrm{Cl})$ \\
\hline Total & 107,258 & 100,00 \\
\hline \multicolumn{3}{|l|}{ Sex } \\
\hline Male & 56,782 & $52.9(52.6 ; 53.2)$ \\
\hline Female & 50,476 & $47.1(46.8 ; 47.4)$ \\
\hline \multicolumn{3}{|l|}{ Age group, years } \\
\hline $15-49$ & 9332 & $8.7(8.5 ; 8.9)$ \\
\hline $50-69$ & 33,344 & $31.1(30.8 ; 31.4)$ \\
\hline$\geq 70$ & 64,582 & $60.2(59.9 ; 60.5)$ \\
\hline \multicolumn{3}{|l|}{ Type of stroke } \\
\hline Ischemic & 66,261 & $61.8(61.5 ; 62.1)$ \\
\hline Hemorrhagic & 40,997 & $38.2(37.9 ; 38.5)$ \\
\hline Epidemiologic indicators & \multicolumn{2}{|c|}{ Value (per 100,000 inhabitants) } \\
\hline Incidence & \multicolumn{2}{|l|}{138.91} \\
\hline Prevalence & \multicolumn{2}{|l|}{1008.02} \\
\hline Mortality & \multicolumn{2}{|l|}{63.15} \\
\hline MIR & \multicolumn{2}{|l|}{0.06} \\
\hline DALYS & \multicolumn{2}{|l|}{1437.74} \\
\hline YLD & \multicolumn{2}{|l|}{14.77} \\
\hline YLL & \multicolumn{2}{|l|}{1331.74} \\
\hline
\end{tabular}

CI confidence interval, DALYs disability-adjusted life years, MIR mortality-toincidence ratio, $Y L D$ years lived with disability, $Y L L$ years of life lost i). Most of the epidemiological indicators of stroke burden are higher in men than in women.

ii). Women have a higher prevalence of hemorrhagic stroke and more years of disability (YLD) than men.

iii). Both stroke in general and hemorrhagic subtype present higher mortality indicators in individuals aged $15-49$ years.

The Stroke Association reported in 2018 [16] that men are more likely to experience a stroke than women because men are more prone to alcoholism and smoking, which are important risk factors for cardiovascular and metabolic diseases.

In the period between 2005 and 2015, the trend of stroke mortality was constant, with a higher number of deaths from the disease in 2007 and 2008, affecting more men, individuals over 65 years of age and white individuals [17].

Studies conducted by the National Health Survey (2013) revealed that stroke mostly affects older people, those without a formal education, and residents of urban centers. In addition, more men than women are affected by stroke leaving functional disabilities in this public [18]. An addition, men are still considered to comprise the majority of people affected by stroke [19].

However, the present study observed that women had a higher prevalence of hemorrhagic stroke and more YLD than men. The high chance of hemorrhagic stroke in women has already been documented in some studies, including in Latin American countries. Diaz et al. demonstrated a high incidence of hemorrhagic stroke in females associated mainly with alcohol intake, smoking, hypertension and dyslipidemia [20,21].

At the same time, women have some unique risk factors, such as hormonal changes caused by hormonal contraception, pregnancy, childbirth, and hormone replacement therapy [22]. In this regard, many studies show that the prevalence is higher in women, as found in the present study.

Women have a higher YLD compared to men in hemorrhagic stroke, which could also give an indication of this important female increase in the epidemiology of this type of stroke The YLD reflects one of the most alarming data on stroke. Individuals 70 and older have worse indices in all groups and types of stroke studied, which shows the urgency of the need for care and followup of this population after stroke. In addition, there are differences between sex and type of stroke [20,21].

In Brazil, aging is the strongest non-modifiable risk factor for ischemic stroke, and elderly stroke patients have higher mortality and morbidity and worse functional recovery than younger patients [23]. Although high 
Table 3 Stroke epidemiology according to stroke type and sex in Brazil in 2016

\begin{tabular}{|c|c|c|c|c|c|}
\hline \multirow[t]{2}{*}{ Indicators } & \multicolumn{2}{|l|}{ Sex } & \multicolumn{3}{|c|}{ Age group } \\
\hline & Male & Female & $\begin{array}{l}15- \\
49 \text { years }\end{array}$ & $\begin{array}{l}50- \\
69 \text { years }\end{array}$ & $\geq 70$ years \\
\hline \multicolumn{6}{|l|}{ Overall } \\
\hline Incidence & 160.13 & 122.9 & 32.78 & 298.58 & 971.78 \\
\hline $\begin{array}{l}\text { Preva- } \\
\text { lence }\end{array}$ & 1153.94 & 897.44 & 264.9 & 2267.69 & 6816.73 \\
\hline Mortality & 80.68 & 51.15 & 8.2 & 88.7 & 599.9 \\
\hline MIR & 0.50 & 0.41 & 0.25 & 0.039 & 0.09 \\
\hline DALYS & 1437.74 & 961.87 & 403.58 & 2587.61 & 7160.72 \\
\hline YLD & 106 & 99 & 23.92 & 196.36 & 783.89 \\
\hline YLL & 1331.74 & 862.87 & 379.66 & 2391.25 & 6376.83 \\
\hline \multicolumn{6}{|l|}{ Ischemic } \\
\hline Incidence & 120.6 & 85.16 & 403.58 & 2587.61 & 7160.72 \\
\hline $\begin{array}{l}\text { Preva- } \\
\text { lence }\end{array}$ & 1018.7 & 731.22 & 207.38 & 1857.22 & 6085.24 \\
\hline Mortality & 54.17 & 32.48 & 1.27 & 41.59 & 456.83 \\
\hline MIR & 0.44 & 0.04 & 0.0031 & 0.022 & 0.075 \\
\hline DALYS & 814.66 & 490.28 & 72.75 & 1215.72 & 5393.9 \\
\hline YLD & 91.22 & 78.38 & 16.73 & 157.01 & 681.21 \\
\hline YLL & 723.44 & 411.9 & 56.02 & 1058.71 & 4712.69 \\
\hline \multicolumn{6}{|c|}{ Hemorrhagic } \\
\hline Incidence & 39.53 & 37.74 & 13.68 & 87.64 & 218.08 \\
\hline $\begin{array}{l}\text { Preva- } \\
\text { lence }\end{array}$ & 170.99 & 201.64 & 83.57 & 453.29 & 901.91 \\
\hline Mortality & 26.51 & 18.68 & 6.93 & 47.1 & 143.1 \\
\hline MIR & 0.67 & 0.09 & 0.50 & 0.1 & 0.16 \\
\hline DALYs & 623.08 & 471.59 & 330.83 & 1371.89 & 1766.82 \\
\hline YLD & 14.77 & 20.62 & 7.19 & 38.34 & 102.68 \\
\hline YLL & 608.31 & 450.97 & 323.64 & 1333.55 & 1664.14 \\
\hline
\end{tabular}

$D A L Y$ s disability-adjusted life years, MIR mortality-to-incidence ratio, $Y L D$ years lived with disability, YLL years of life lost

cerebrovascular accident rates occur in individuals older than 70 years, in 2016, both stroke in general and hemorrhagic subtype present higher mortality indicators in individuals aged $15-49$ years [24].

Stroke in individuals over 70 years of age is a disabling disease, related to a longer period of living with sequelae and causing the burden of disease to be higher in this specific age group [25], as found in the present study.

Data on DALYs reflect a greater loss of economic productivity in both sexes and stroke types, but with more significant numbers in men aged 50-69 years in which they are still economically active. At the same time, the YLL numbers reinforce the thesis that men still lose many more years of life due to ischemic stroke, but this difference decreases in relation to females when we discuss hemorrhagic stroke. This could be explained by the considered increase of cases of this modality of disease in the women in the last years [20,21].
In contrast to Brazilian statistics, in other countries, stroke is more common in younger individuals and in individuals in economically active age groups [4]. The Stroke Association [16] reported that in countries such as the United States and the United Kingdom, the rate of stroke for the first time in people aged 45 years or older is expected to increase over the next 20 years.

Cardiovascular disease mortality in Brazil is one of the highest among the Latin American countries, and although this mortality rate has declined in recent years (between 1980 and 2002), the decrease has not been consistent different regions, and the Northeast still shows higher rates $[17,18]$.

In addition, Brazil is a country with a vast territorial extension and cultural plurality that undergoes constant socioeconomic and political changes. In this sense, other epidemiological studies that consider socioeconomic, demographic, and cultural aspects in a longitudinal design should be encouraged.

In Brazil, in 2016, the burden of stroke affected more men and individuals over the age of 70 in general, but the prevalence of hemorrhagic stroke was more striking in women. It is also women who experience the most disabilities, although men die more frequently. In addition, stroke has a high lethality in individuals aged $15-49$ years.

The differences in morbidity and mortality from stroke are not only observed in Brazil, but in most Latin American and developing countries. Thus, each country should take into account the prevention of the classic risk factors for cardiovascular diseases, respecting the epidemiological, cultural and socioeconomic realities of each region. This would be possible through greater regional freedom to create and implement prevention programs. In Brazil, for example, this would be possible through the Basic Health Units. Coverage has been increasing in recent years and it is possible to become an instrument for the promotion and prevention of diseases with greater epidemiological importance, as is already done with breast cancer and of cervix of uterus $[26,27]$.

\section{Limitations}

The limitations of this study are its descriptive nature and the fact that it is only a snapshot in time and not a longitudinal analysis.

\section{Abbreviations}

GBD: Global Burden of Disease; DALYs: disability-adjusted life years; MIR: mortality-to-incidence ratio; YLD: years lived with disability; YLL: years of life lost.

\section{Authors' contributions}

NMS, FWSF and JAC contributed to concept, writing and revising the manuscript. FWSF, DMML, FMS, FA, LCPC and JAC have made substantial 
contributions to conception and design, or acquisition and interpretation of data. FWSF, FMS and DMML participated in the statistical analysis. FMS, FA, LCPC and JAC have also been involved in drafting the manuscript or revising it critically for important intellectual content. Each author have participated sufficiently in the work to take public responsibility for appropriate portions of the content for the final approval of the version to be published. All authors agreed to be accountable for all aspects of the work in ensuring that questions related to the accuracy or integrity of any part of the work are appropriately investigated and resolved. All authors read and approved the final manuscript.

\section{Author details}

${ }^{1}$ Faculdade de Medicina do ABC, Santo André, SP, Brazil. ${ }^{2}$ Laboratório de Epidemiologia e Análise de Dados, Faculdade de Medicina do ABC, Santo André, SP, Brazil. ${ }^{3}$ Disciplina de Angiologia e Cirurgia Vascular, Faculdade de Medicina do ABC, Santo André, SP, Brazil.

\section{Acknowledgements}

Not applicable.

\section{Competing interests}

The authors declare that they have no competing interests.

\section{Availability of data and materials}

The datasets generated during and/or analyzed during the current study are not publicly available due, however it can be requested to the corresponding author on reasonable request.

\section{Consent to publication}

Not applicable.

Ethics approval and consent to participate

Not applicable.

\section{Funding}

Not applicable.

\section{Publisher's Note}

Springer Nature remains neutral with regard to jurisdictional claims in published maps and institutional affiliations.

Received: 4 September 2018 Accepted: 10 October 2018 Published online: 16 October 2018

\section{References}

1. Feigin VL, Lawes CM, Bennett DA, Barker-Collo SL, Parag V. Worldwide stroke incidence and early case fatality reported in 56 population-based studies: a systematic review. Lancet Neurol. 2009;8(4):355-69.

2. Avezum Á, Costa-Filho FF, Pieri A, Martins SO, Marin-Neto JA. Stroke in Latin America: burden of disease and opportunities for prevention. Glob Heart. 2015;10(4):323-31.

3. Sofer D. Study assesses the global stroke burden. Am J Nurs. 2016;116(9):16.

4. da Silva Paiva L, Schoueri JHM, de Alcantara Sousa LV, Raimundo RD, da Silva Maciel E, Correa JA, et al. Regional differences in the temporal evolution of stroke: a population-based study of Brazil according to sex in individuals aged 15-49 years between 1997 and 2012. BMC Res Notes. 2018;11(1):326.

5. Garritano CR, Luz PM, Pires ML, Barbosa MT, Batista KM. Analysis of the mortality trend due to cerebrovascular accident in Brazil in the XXI century. Arq Bras Cardiol. 2012;98(6):519-27.

6. McCarron P, McCarron MO, Murray L, Kee F. Secular trends in stroke mortality and early-life environment. Lancet. 2003;361(9362):1059-60.

7. de Melo Lucena DM, Dos Santos Figueiredo FW, de Alcantara Sousa LV, da Silva Paiva L, do Carmo Almeida TC, Galego SJ, et al. Correlation between municipal human development index and stroke mortality: a study of Brazilian capitals. BMC Res Notes. 2018;11(1):540.
8. Forouzanfar MH, Alexander L, Anderson HR, Bachman VF, Biryukov S, Brauer $\mathrm{M}$, et al. Global, regional, and national comparative risk assessment of 79 behavioural, environmental and occupational, and metabolic risks or clusters of risks in 188 countries, 1990-2013: a systematic analysis for the Global Burden of Disease Study 2013. Lancet. 2015;386(10010):2287-323.

9. Goldstein LB, Bushnell CD, Adams RJ, Appel L, Braun LT, Chaturvedi S, et al. Guidelines for the primary prevention of stroke: a guideline for healthcare professionals from the American Heart Association/American Stroke Association. Stroke. 2011;42(2):517-84.

10. Lukasik M, Kozubski W. Metabolic syndrome as the risk factor for ischaemic stroke. Neurol Neurochir Pol. 2012;46(3):271-8.

11. Roever L, Resende ES, Diniz ALD, Penha-Silva N, O'Connell JL, Gomes PFS, et al. Metabolic syndrome and risk of stroke: protocol for an update systematic review and meta-analysis. Medicine (Baltimore). 2018;97(15):e9862.

12. Liu Q, Li YX, Hu ZH, Jiang XY, Li SJ, Wang XF. Comparing associations of different metabolic syndrome definitions with ischemic stroke in Chinese elderly population. Eur J Intern Med. 2018;47:75-81.

13. Lozano R, Naghavi M, Foreman K, Lim S, Shibuya K, Aboyans V, et al. Global and regional mortality from 235 causes of death for 20 age groups in 1990 and 2010: a systematic analysis for the Global Burden of Disease Study 2010. Lancet. 2012;380(9859):2095-128.

14. Murray CJ, Vos T, Lozano R, Naghavi M, Flaxman AD, Michaud C, et al. Disability-adjusted life years (DALYs) for 291 diseases and injuries in 21 regions, 1990-2010: a systematic analysis for the Global Burden of Disease Study 2010. Lancet. 2012;380(9859):2197-223.

15. Murray CJ, Ezzati M, Flaxman AD, Lim S, Lozano R, Michaud C, et al. GBD 2010: design, definitions, and metrics. Lancet. 2012;380(9859):2063-6.

16. Benjamin EJ, Virani SS, Callaway CW, Chamberlain AM, Chang AR, Cheng S, et al. Heart disease and stroke statistics-2018 update: a report from the American Heart Association. Circulation. 2018;137(12):e67-492.

17. Araújo JPd, Darcis JW, Tomas ACV, Mello WAd. Mortality trend due to cerebrovascular accident in the city of Maringá, Paraná between the years of 2005 to 2015. Int J Cardiovasc Sci. 2018;31:56-62.

18. Bensenor IM, Goulart AC, Szwarcwald CL, Vieira MLFP, Malta DC, Lotufo PA. Prevalence of stroke and associated disability in Brazil: national health survey-2013. Arq Neuropsiquiatr. 2015;73:746-50.

19. Kim WS, Cho S, Baek D, Bang H, Paik NJ. Upper extremity functional evaluation by Fugl-Meyer assessment scoring using depth-sensing camera in hemiplegic stroke patients. PLOS ONE. 2016;11(7):e0158640.

20. Díaz V, Cumsille MA, Bevilacqua JA. Alcohol and hemorrhagic stroke in Santiago, Chile. a case-control study. Neuroepidemiology. 2003;22(6):339-44.

21. Arnao V, Acciarresi M, Cittadini E, Caso V. Stroke incidence, prevalence and mortality in women worldwide. Int J Stroke. 2016;11(3):287-301.

22. de Carvalho JJ, Alves MB, Viana G, Machado CB, dos Santos BF, Kanamura $\mathrm{AH}$, et al. Stroke epidemiology, patterns of management, and outcomes in Fortaleza, Brazil: a hospital-based multicenter prospective study. Stroke. 2011;42(12):3341-6.

23. Porcello Marrone LC, Diogo LP, de Oliveira FM, Trentin S, Scalco RS, de Almeida AG, et al. Risk factors among stroke subtypes in Brazil. J Stroke Cerebrovasc Dis. 2013;22(1):32-5.

24. Bushnell C, Howard VJ, Lisabeth L, Caso V, Gall S, Kleindorfer D, et al. Sex differences in the evaluation and treatment of acute ischaemic stroke. Lancet Neurol. 2018;17(7):641-50.

25. Sousa LVA, Paiva LDS, Figueiredo FWDS, Almeida TCDC, Oliveira FR, Adami F. Trends in stroke-related mortality in the ABC region, São Paulo, Brazil: an ecological study between 1997 and 2012. Open Cardiovasc Med J. 2017;11:111-9.

26. Colgrove P, Connell KL, Lackland DT, Ordunez P, DiPette DJ. Controlling hypertension and reducing its associated morbidity and mortality in the Caribbean: implications of race and ethnicity. J Clin Hypertens (Greenwich). 2017;19(10):1010-4.

27. Soares Neto JJ, Machado MH, Alves CB. O Programa Mais Médicos, a infraestrutura das Unidades Básicas de Saúde e o Índice de Desenvolvimento Humano Municipal. Cien Saude Colet. 2016;21:2709-18. 